\title{
New design concept of a tank made of plastic material for firefighting vehicle
}

\section{Collotta*and L. Solazzi}

\author{
Department of Mechanical and Industrial Engineering, \\ University of Brescia, via Branze, 38 Brescia, ITALY \\ *Email: m.collotta@unibs.it \\ Phone: +393287493932; Fax: +6094246222
}

\begin{abstract}
Optimisation work has been increasingly directed at commercial vehicles to reduce their weight and thus enhance their performance. This optimisation, which responds to the requirements of various European standards with regard to the reduction of fuel consumption, also involves the elements mounted on these vehicles. This work discusses the development and design of a firefighting vehicle tank made from plastic material instead of the usual structure or stainless steel, essentially to reduce the weight of the structure. The design and construction feasibility of the components have been developed based on the specifications required. These specifications concern the tank capacity to resist at different load conditions and avoid any external vibrations. To ensure this, the tank consists of a number of internal welded plates in order to reduce the sloshing effect and secondly makes it modular and thus highly adaptable to the customer's needs. Specific method on the production of the component is also provided. Therefore, numerical tests were conducted with linear elastic stress analysis with square brick elements. The boundary conditions applied to the numerical model provide a complete support to the panels and are determined by the load condition of fluid used. This preliminary analysis was conducted to define the thickness of the tank panels and revealed that the use of a plastic tank leads to a weight reduction of about $35 \%$ and generates cost savings of about $25-30 \%$ compared to the steel equivalent. Therefore, the use of plastic materials compared to the classic materials seems to be very positive and this is critical information to support the final decision in a regulated sector, where the firefighting vehicles are.
\end{abstract}

Keywords: Plastic material structure designs; tank, vessel; commercial vehicle; Finite Element Analysis analysis; mechanical structure.

\section{INTRODUCTION}

Firefighting vehicles are a special and regulated category of vehicles that must meet specific performances. They are multiple use vehicles called, for example, to operate at airports or fight forest fires. In general, they are required to have a tank to contain the firefighting liquid, which may be water or a foaming agent capable of preventing oxygen from reaching the flames and thus "smothering" the fire [1,2]. In addition, there is also a much smaller tank, which can contain an additive to be used in association with the liquid in the main tank. The tank must also be fitted with a suitable plumbing system, both for liquid intake and delivery to the fire hoses or the "cannon" generally installed on the vehicle's roof and controlled from inside the cab [3,4]. Additional to these fundamental 
components, a compartment to house the accessories (pipes, ladders, lighting equipment, etc.) is required. All these must be secured to what is normally a commercial truck chassis; automotive companies sell the "bare" vehicle, which must be fitted with the components described above. Figure 1 shows a number of different firefighting vehicles.
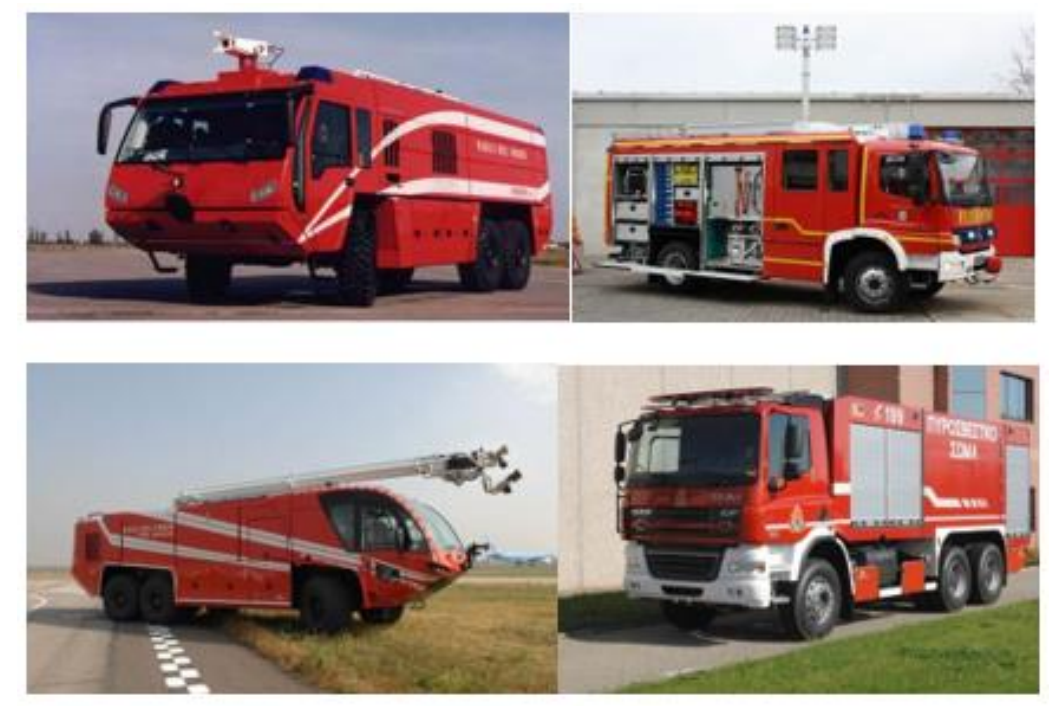

Figure 1. A few different types of firefighting vehicles [5].

From the brief outline provided above, it is clear that two main factors influencing the firefighting systems are the weight of the vehicle [6], and tank load capacity. Furthermore, reducing weight will lead to a decrease in fuel consumption and thus cut transportation costs according to the EU standards [7]. The vehicle's weight can be optimised either through its structural design with the aid of more reliable calculation methods or by using experimental data obtained by reproducing the real operating load condition as shown in a study [8]. Another factor is related to the type of materials [9], for example, adopting a high strength steel, aluminium, plastic or composite solution, instead of the conventional stainless steel [10-12]. The aim of this study is to determine the performance and design of a firefighting vehicle tank with the lightest weight. Moreover, this study underlines benefits of the design of a plastic tank compared to conventional solution made with stainless steel $[13,14]$. Also, this technological solution makes feasible larger the tank dimension that otherwise could not be made with a fibre glass solution [15]. For example, the use of plastic material inside the tank could present a positive solution for internal components as undercuts and longitudinal structures.

\section{MATERIALS AND METHODS}

\section{Design Specification}

The design specifications for the tank are as follows: total volumetric capacity 70001 , the presence of two separate compartments (6000 1 and 1000 1) to allow the use of two liquids/foam agents to extinguish fires, and suitable for connecting to and transporting on a truck. With regard to the latter, the maximum width must be less than $2550 \mathrm{~mm}$ and the height must be suitable for both the type of truck and subframe to be fixed to the chassis of the vehicle itself. Practically, the height must be $1500 \mathrm{~mm}$. Another factor for consideration is that the tank must contain a series of pipelines for fluid intake and delivery as well as a series of gauges to indicate the level of the fluid inside it. 


\section{Methodology Used and Load Conditions}

The methodology adopted has implemented a preliminary dimension of a tank made of different materials. The tank was exposed to a wide variety of load conditions, depending on the operating conditions (in terms of the level of maintenance, wear, and tear) of the vehicle and type of road on which it is travelling. The stiffness of the vehicle in terms of chassis stiffness, suspension, and type of route has been influenced by stress induced by the road. Moreover, the literature provides some analytical and experimental models to determine the effect induced by fluids on the internal plate of the tank. It is also important to underline that fluid movement and stresses are correlated to the dynamics and handling of the vehicle [16-18]. This factor is also evident in the case of a vehicle subjected to an acceleration such as during a shape or a breaking phase $[19,20]$. Two other important factors related to the magnitude of these stresses are the geometry [21] and the tank filling level of filling of the tank [22-24]. On the basis of the data available in the literature and from previous works [8], the load conditions reported in Table 1 are considered.

Table 1. Load conditions ( $\mathrm{g}=$ gravity acceleration).

\begin{tabular}{lll}
\hline Type of load condition & Entity & Direction \\
\hline Acceleration & $0.5^{*} \mathrm{~g}$ & Longitudinal \\
Braking & $0.8^{*} \mathrm{~g}$ & Longitudinal \\
Cornering & $0.7^{*} \mathrm{~g}$ & Transversal \\
Crossing of curb or bump & $2.0^{*} \mathrm{~g}$ & Vertical \\
\hline
\end{tabular}

Another load condition normally overlooked is the torsion to which the tank is subjected when the vehicle is climbing or cornering, or when the height of one of its wheels changes (due to a pothole or bump). In general, the torsion of the vehicle also affects the chassis and subframe (the structure interfaced between the vehicle chassis and the tank, or in more general term, the body) [25]. Since the tank is generally stiffer than the chassis (the cross-section of the tank is virtually circular, while the chassis consists of two parallel C-rails), the tank becomes the torsion-limiting element and thus is subjected to the stresses induced by the twisting of the vehicle. The conditions described above were used when calculating and verifying the tank dimensions.

\section{Main Characteristics of New Tank}

The volumetric capacity of the new tank depends on the customer's specifications; in this case, they are 70001 . The key structural factor is that the tank must withstand the stresses generated both by the liquid inside it and the truck when travelling on the road with a satisfactory safety factor. The fixing of the tank to the vehicle's subframe is particularly important. The tank is secured with bolts, which are the focal point of all the forces generated by the oscillation of the tank [26]. It must also be designed and controlled considering the real operating conditions, such as the corrosion phenomena [27]. For example, if the salt applied to roads comes into contact with steel bolts, it increases their rate of corrosion considerably; corresponding to a reduction in strength is needed. An additional factor is that the tank must contain a series of baffles and/or partitions, intended not only to stiffen the structure but also, and above all, distribute the shaking motion of the liquid over a number of surfaces. For example, if the truck breaks sharply having a tank without baffles, the dynamic action generated by all the fluid will act on the front wall of the tank, whereas if internal baffles are provided, only a portion of the stresses generated will reach the tank's front wall. Therefore, chemical resistance and non-toxicity 
may be the key factors in this new kind of tank. The geometry of baffles also plays an important role in avoiding the effect of fluid slosh [28, 29]. Moreover, the effects of baffles on the performance of the vehicle have been presented in the literature, in particular on the dynamic behaviour of the braking phase [30, 31].

\section{Characteristics of the Material Used}

It was decided that the material used for the construction of the tank should be changed in order to reduce its weight and also optimise its shape. Suitable structural materials available on the market as alternatives to conventional structural steel include high strength steel (with tensile stress about $3 / 2$ times that of conventional construction steels), aluminium alloys, composite materials, and plastics [32-35]. The choice of material depends on a number of factors, some of which are listed below. The first is the overall cost, not only of purchasing the material but also relating to design, interfacing with the truck chassis, and construction of the tank (aspects correlated to technical factors), and post-construction treatments. Some of the main parameters which must be considered with regard to the structural aspects are the density (correlated to the weight of the tank), Young's modulus (correlated to the deformation of the component) and strength of the material itself. The conventional method for optimising the ratio between the material's density and its strength is the use of the Ashby plots [36, 37], which reveal that composite material, i.e., polymer reinforced with carbon or glass fibre, is one of the best-performing materials. However, this is particularly expensive, and the construction of the tank would require considerable investment in equipment, which could only be recovered if a large number of highly standardised components were produced. Moreover, the construction of the internal baffles, especially the joints between them and the walls of the tank, would be technologically problematic if a composite was used. Other important factors are related to the coating and finishing to be used, either to give the tank "immunity" to the corrosive phenomena triggered by the fluid or foam it contains, or to make it suitable for the transportation of liquids for human consumption (water). Last but not least, the choice of material also depends on the supplier/producer's capability to produce the material required to construct the tank on a reliable basis. In response to the factors outlined above, the material chosen for the construction of the tank was plastic, specifically polypropylene copolymer (PPC). Its main characteristics are reported in Table $2[38,39]$.

Table 2. Material characteristics.

\begin{tabular}{ll}
\hline Characteristics & Value \\
\hline Density & $0.9 \mathrm{~kg} / \mathrm{dm}^{3}$ \\
Resistance to abrasion & Good \\
Weldability & Good \\
Thermal and Electrical Insulation & Good \\
Resistance to acid and alkaline solutions & Excellent \\
Melting point & $>150^{\circ} \mathrm{C}$ \\
\hline
\end{tabular}

Other factors which should not be overlooked when choosing plastic are related to ageing, the glass transition temperature, etc. In terms of the specific use of the tank, the liquid it contains should also be considered. For example, some foaming agents are acids (1.4 times the $\mathrm{pH}$ of water), or at times the tanker trucks may be used for transporting drinking water. The main mechanical characteristics are reported in Table 3. 
Table 3. Mechanical characteristics.

\begin{tabular}{ll}
\hline Characteristics & Value \\
\hline Ultimate tensile stress & $25[\mathrm{MPa}]$ \\
Young's Modulus, E & $1200[\mathrm{MPa}]$ \\
Elongation at ultimate strength & $>300 \%$ \\
\hline
\end{tabular}

\section{RESULTS AND DISCUSSION}

\section{Dimensioning of the Tank}

Considering the component and material used, the tank consists of a series of plates/sheets welded together to create the complete unit. Therefore, the preliminary and dimensioning analyses can be carried out by using plates and applying a pressure on the surface which depends both on the plate's position and load condition considered [40]. These analyses were performed using conventional plate theory and finite element analysis. The software used was Simulation, included in the SolidWorks, a solid modelling produced by Dassault Systems. Numerical analyses were carried out with a linear elastic stress with square brick elements. Preliminary analysis also determined the dimension of the element to obtain a correspondence of results when the dimension of the tank changed. This correspondence was evaluated compared to the theoretical displacements on a simple rectangular geometry shape with those acquired from the FEM model [41]. The minimal dimension of the element was about $5 \mathrm{~mm}$ and considered the computational cost of analysis and analysis time. This result was almost $1 / 2$ of the minimum thickness of of the tank panels. Therefore, this preliminary analysis is important to determine the thickness of the panels. The boundary condition applied in the numerical model provides a support on the entire panel, while the load condition is a function of the position of the panel. In general, load condition on the panels can be defined by the stress of the fluid as presented in Table 1. An example of this analysis is provided in

Figure 1, which illustrates the maximum stress and displacement on the bottom wall of the tank (size $1500 \times 850 \mathrm{~mm}$ ). The FEM model of this component is composed of 161000 elements for a total of about 795000 degrees of freedom.
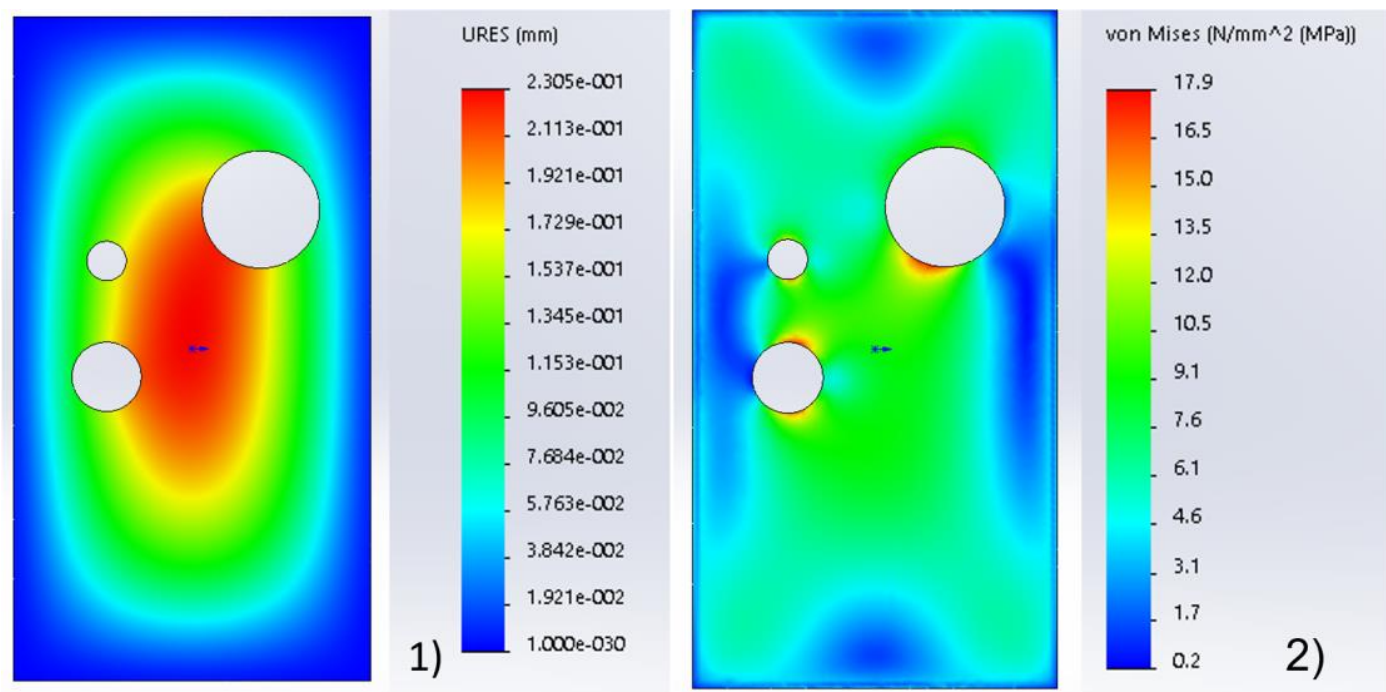

Figure 1. Results of FEM analysis on the bottom plate: 1) distribution of displacements $[\mathrm{mm}]$; and 2) distribution of stresses [MPa]. 
Figure 2 shows the uniform stress on the plate. Also, it presents the maximum displacement in correspondence to the central area (this is related to the thickness of the panel itself). Moreover, in Figure 2, the stress intensity factor generated by the holes is also presented. These holes have the function of filling, emptying, transferring or mixing fluids inside both tanks (6000 1 and 7000 1). The aim of this preliminary analysis is to determine the wall thickness. There are three constraints: the first is that the material must be able to withstand the forces acting on the plate; the second is that there must not be excessive displacement (a design value of 1/1000 on the longest side of the plate was adopted); and the third is that the thickness used must be commercially available. The limitation of the maximum displacement reduced the maximum stress on the component and in particular on wall panels of the tank. Table 1 shows that the minimum safety coefficient of the last load and with all load conditions as 1,5 , respectively.

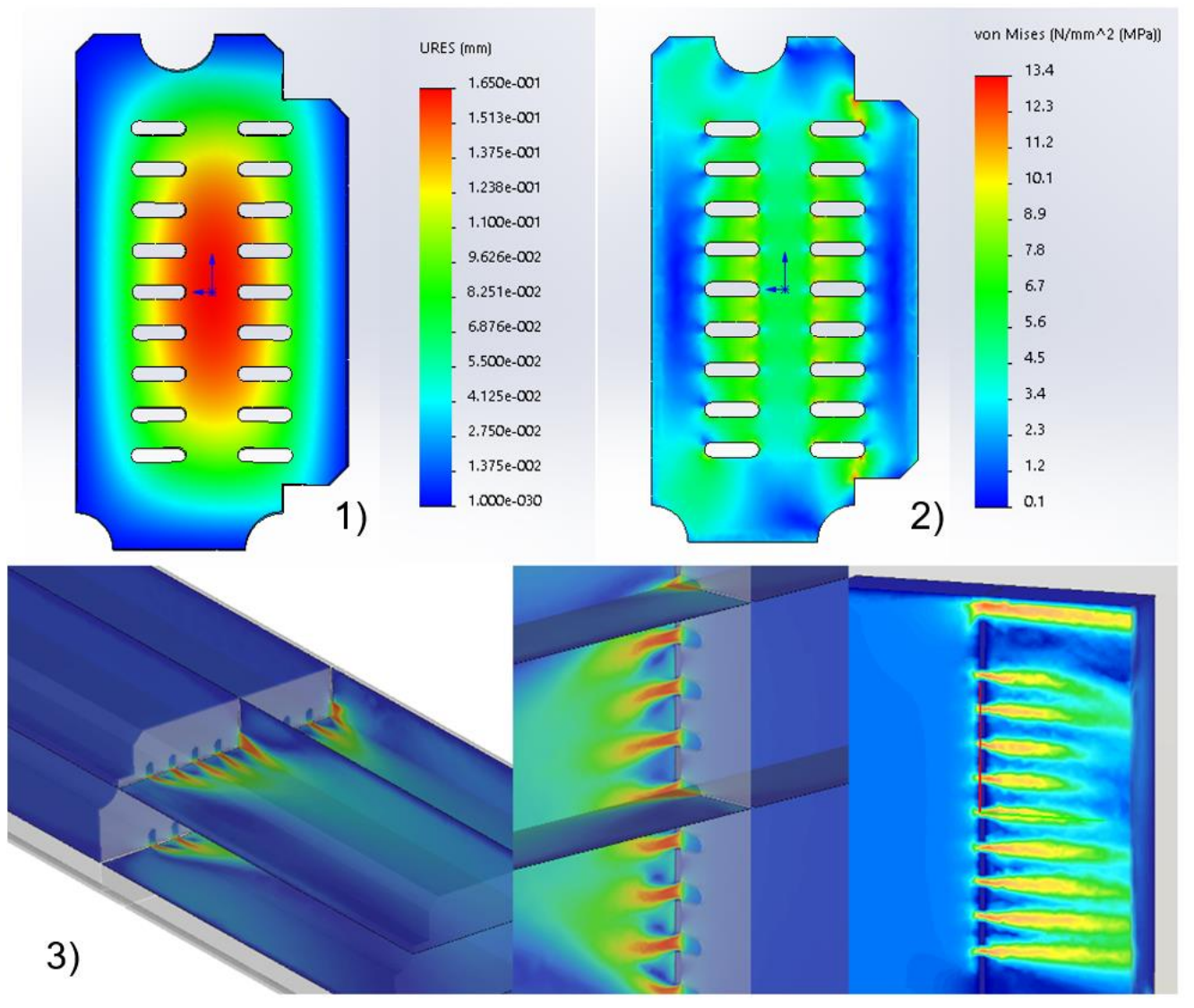

Figure 2. FEM analysis of an internal baffle: 1) distribution of displacements [mm]; 2) distribution of stresses [MPa]; and 3) results of fluid-dynamic analyses.

Figure 2 illustrates the numerical analyses performed on an internal baffle. It shows the apertures were provided to allow the fluid to move between the various sections of the tank. The form of these apertures was decided by means of a series of fluid dynamic/structural analyses $[28,29,42]$, both to provide the highest possible head loss and guarantee an appropriate safety factor. Based on the determination of internal and external plates, an overall analysis was performed on the structural mechanical behaviour of the tank (in terms of stresses and displacements). Moreover, a number of structural 
phenomena were assessed in this study, for example, the interaction between the external and internal plates and phenomena related to the plates' instability. Furthermore, the overall dynamic behaviour was assessed. Due to the adoption of a series of modal analyses, the primary structure self-frequencies and its primary vibration modes were analysed. Furthermore, all the dynamic forces which may have an effect on the tank from the road (wheels, tires and suspensions) or from the engine were determined. The FEM model was elaborated in order to follow the preliminary analysis of the single main panels and in particular the size and numerical elaboration of the finite element. During the analysis, the entire tank adopted a dimension of $5 \mathrm{~mm}$ in the areas with a high-stress gradient. The constraint conditions imposed were rigid constraints in the attachment point (i.e., on the base of the tank). The images in

Figure 3 illustrate the displacements calculated for the tank when the truck is cornering with the acceleration of $0.7 \mathrm{~g}$. The range of the displacements (maximum value of about $20 \mathrm{~mm}$ ) was absolutely acceptable for this load condition. The maximum stresses were concentrated at the base of the tank, where it bolted to the subframe. Special precautions were adopted in this zone, such as the addition of suitable washers underneath the head of the bolts to distribute the stresses across a wider area.

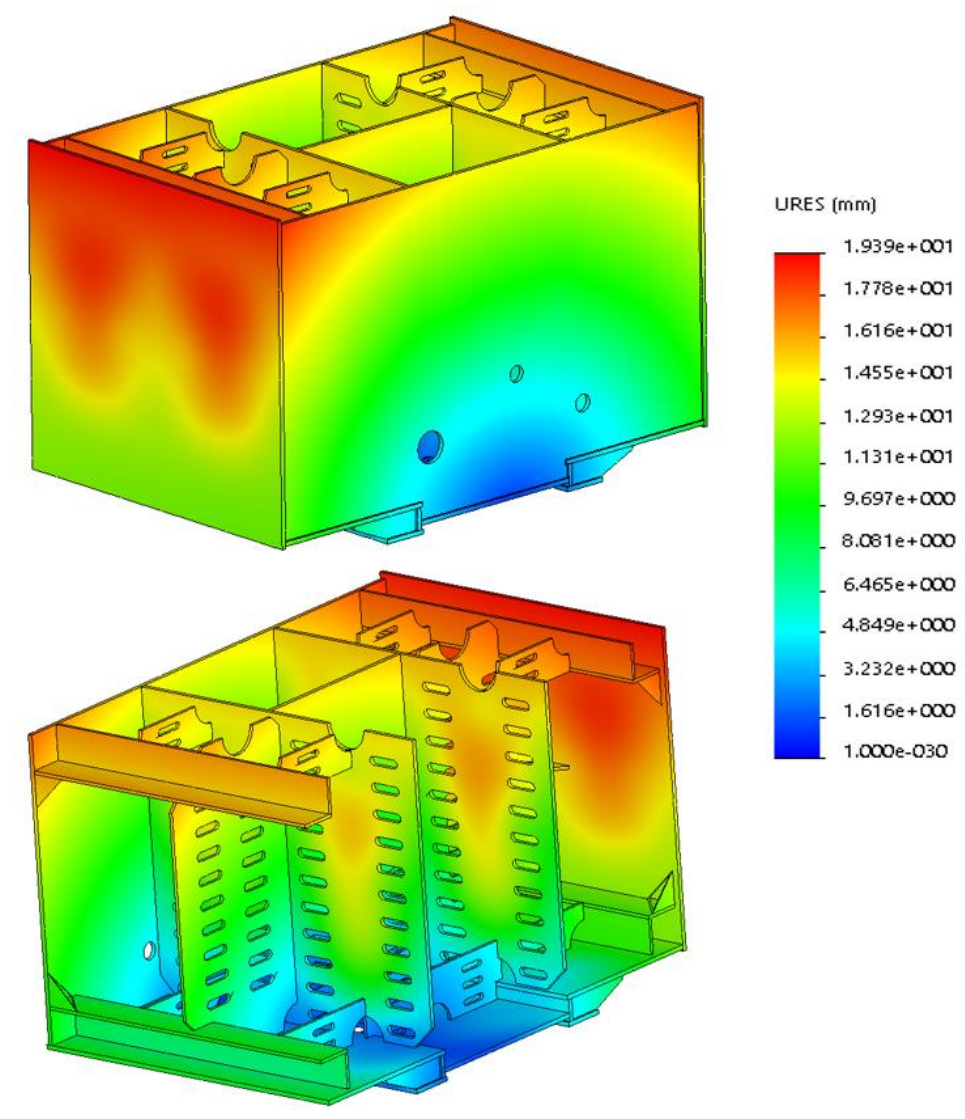

Figure 3. Results of FEM analysis. Displacements (external and internal views) in the load condition when the truck is cornering with the acceleration of $0.7 \mathrm{~g}$.

The images in

Figure 4 illustrate the structure's first six natural-vibration modes. The first two modes involved the rigid body vibration of the structure, and the modal participation factors were about $40 \%$ of the total mass for the first mode $(\mathrm{fl}=35.4 \mathrm{~Hz})$ and about $30 \%$ 
for the second mode ( $\mathrm{f} 2=35.7 \mathrm{~Hz}$ ). The other vibration modes involved both the external walls and internal baffles of the tank (f3 $=89.9 \mathrm{~Hz}, \mathrm{f} 4=103.5 \mathrm{~Hz}, \mathrm{f} 5=108.6 \mathrm{~Hz}, \mathrm{f} 6=118.2$ $\mathrm{Hz}$ ). In the last case, the modal participation factors were low, about $2 \%-5 \%$ for all modes and therefore, they were not significant for the dynamic structural behaviour of the tank [43]. Values of the first natural frequencies were sufficiently high to avoid resonance phenomena induced by the stresses coming from the ground [44, 45].

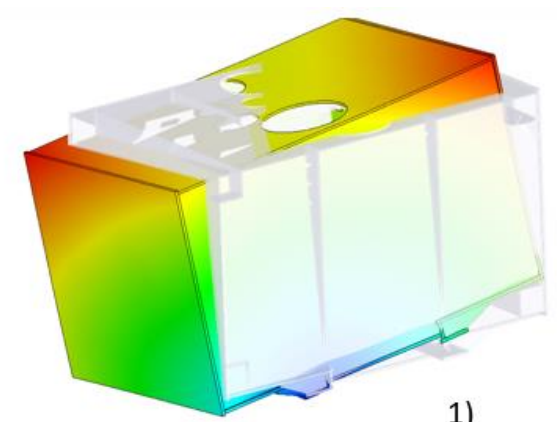

1)

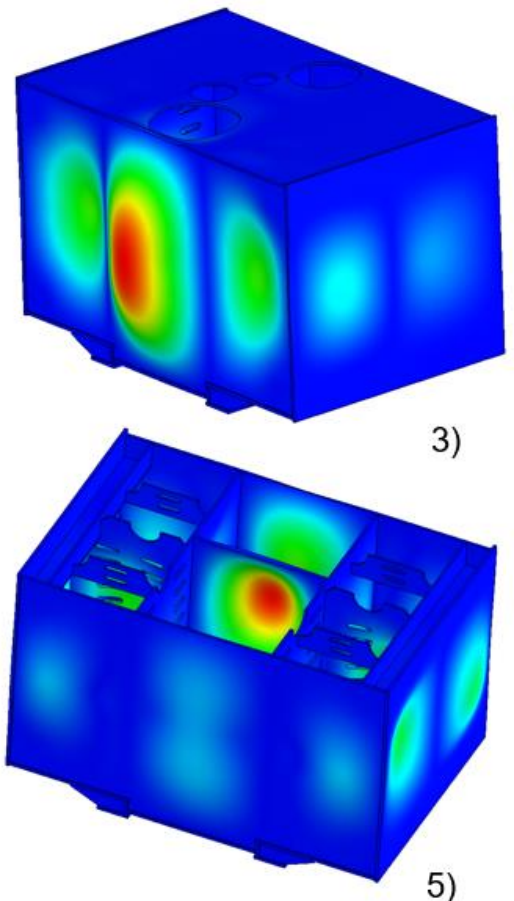

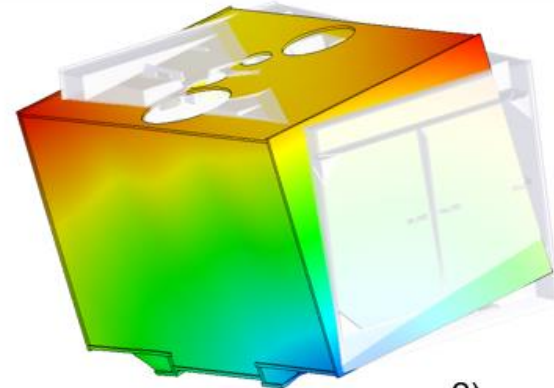

2)

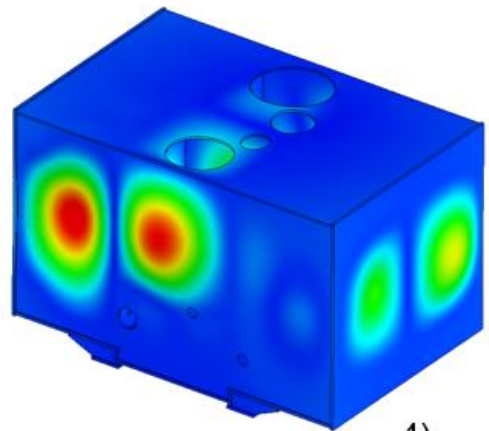

4)

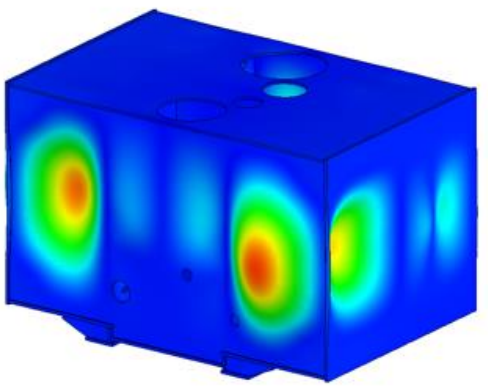

6)

Figure 4. Results of FEM analysis. Displacement trend in the structure's in corresponding to the first natural vibration modes.

The component was constructed with a series of plates in different thicknesses (i.e. 10, 20 or $30 \mathrm{~mm}$ ) depending on the plate's position ( $30 \mathrm{~mm}$ for the bottom, $20 \mathrm{~mm}$ for the side walls, and $10 \mathrm{~mm}$ for the internal baffles). They were shaped in advance to allow them to be assembled together using interlocking joints to form a parallelepiped. Some plates were machined to produce the necessary apertures to allow the fluid to pass and dissipate its energy $[41,45]$. The edges of the plates must be bevelled before welding, carried out with the aid of a special extruder. The assembly procedure allowed all plates to be welded in position. Special attention was also paid to the welding of the elements which secured the tank to the subframe since they were subjected to the most stress under 
all load conditions. This plate-based construction system made it easy to produce tanks of different sizes for ease of adaptation to the customer's needs.

Figure 5 illustrates the tank in its final configuration, where it can be seen clearly that the structure consists of perimeter series plates connected to the internal baffles. The analyses performed indicated that the developed and designed tank was about $10 \%$ lighter than an equivalent tank made by using fibreglass and about $35 \%$ lighter than a tank made of conventional structural steel and/or stainless steel. Moreover, different tests were also performed to establish the mechanical characteristics of the material, especially for welds parts between the plates. The modular design approach using commercial plates was particularly interesting in this study. Furthermore, future development can also continue this approach for a new tank and to optimise the area between the longitudinal beams in the vehicle's chassis. This innovation could be very interesting to move down the centre of gravity of the tank and improve the handling of the entire vehicle.

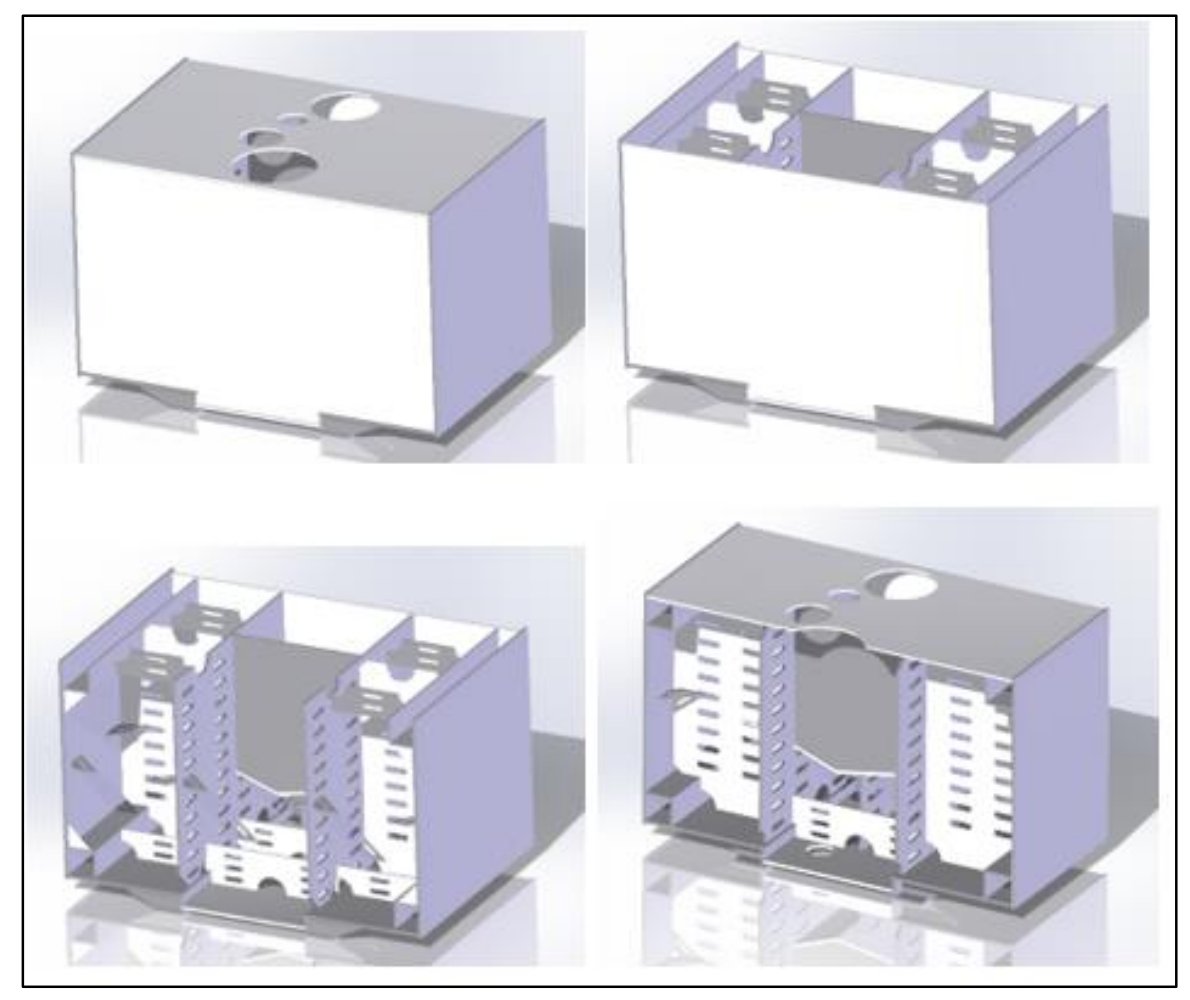

Figure 5.. Final configuration of the tank of $7000 \mathrm{l}$ (width $=2500 \mathrm{~mm}$, height $=1600 \mathrm{~mm}$, depth=1800 mm).

\section{Economic Analysis}

A comparative cost analysis was carried out in order to assess the economic sustainability of the developed firefighting vehicle tank. The production costs of a tank made of plastic material and stainless steel were quantified and compared. An environmental analysis was not conducted in this phase of the process but it is mandatory in the second phase in order to have a better understanding of the tank. In particular, the production process of the two tanks was different. On one hand, we had the moulding production process of PPC, while in the other, steel deformation and welding. Assuming the same quantity of tanks was produced (one firefighting tank) for each case, the components of the tank necessary for the production of the different parts/section were the same. Furthermore, 
we assumed that the differences in the two cases essentially occurred with regard to the materials used and operational costs.

In

Table 1, the costs of the materials for the production of 1 firefighting tank were identified and quantified according to the average prices in the Italian context. In particular, for the plastic firefighting tank, PPC material and operational costs were considered. For the conventional steel firefighting tank, steel material and operational costs were considered. Manufacturing process steps are different (i.e., moulding vs welding and bending); in this direction, the manufacturing costs were different. The resulting cost for one conventional steel firefighting tank was $6134 €$, while for the PPC was $4562 €$. This result assures the economic sustainability of the PPC material developed, as it allows a cost saving of about $26 \%$.

Table 1. Comparative cost analysis.

\begin{tabular}{llll}
\hline \multicolumn{1}{c}{$\begin{array}{c}\text { Innovative PPC } \\
\text { firefighting tank }\end{array}$} & \multicolumn{1}{c}{ Unit cost $[€]$} & $\begin{array}{c}\text { Conventional steel } \\
\text { firefighting tank }\end{array}$ & Unit cost $[€]$ \\
\hline $\begin{array}{l}\text { PPC }(1.5 € / \mathrm{kg}) \\
\begin{array}{l}\text { Polypropylene } \\
\text { operational costs }\end{array}\end{array}$ & 2027 & $\begin{array}{l}\text { Steel }(0.84 € / \mathrm{kg}) \\
\text { Steel operational costs }\end{array}$ & 2880 \\
\hline TOTAL COSTS & 4562 & TOTAL & 6134 \\
\hline
\end{tabular}

The above figures depend on the mass balance of the components, whose main elements are shown in Table 2. As can be seen, the steel material tank is almost $35 \%$ heavier than a plastic equivalent. A decrease in weight influences the environmental sustainability of the system. In fact, a heavier tank implies higher fuel consumption during transportation and it may anyway preclude several other applications. That is because, at the moment, the authors are working to identify a suitable alternative material to replace the initial material and provide a lighter firefighting tank.

Table 2. Comparative weight analysis

\begin{tabular}{lcc}
\hline & $\begin{array}{c}\text { Conventional steel } \\
\text { firefighting tank }\end{array}$ & $\begin{array}{c}\text { Innovative PPC } \\
\text { firefighting tank }\end{array}$ \\
\hline Density $(\mathrm{Kg} / \mathrm{dm} 3)$ & 7.74 & 0.9 \\
Total Weight $(\mathrm{Kg})$ & 3874 & 1352 \\
\hline
\end{tabular}

\section{CONCLUSIONS}

This paper considered the design of a new concept tank for firefighting vehicles, focusing on the importance of material used. This material selection, from a conventional stainless steel to plastic solution, involved complete review of the component's design, which was dimensioned and verified under the application of a wide range of load conditions. In conclusion, a modular construction approach was adopted, involving the production of internal plates for subsequent assembly in the final tank (interlocking joints/welds). This approach also gave a high degree of component modularity, making it very adaptable to the different requirements in terms of capacity and interfacing with the vehicle on which is installed in the tank. Moreover, this technological solution made feasible larger 
dimension and handling of the tank that otherwise could not be made with a steel/fibreglass solution. This preliminary study also presented a considerable lightning and reduction in weight. Indeed, the component designed provided a considerable reduction in weight of about $35 \%$ compared to an equivalent stainless steel tank with a cost saving of about $25-30 \%$. The work was also still in the experimental phase since the first prototype to be used for the necessary trials was still under construction.

\section{ACKNOWLEDGEMENTS}

The authors would like to thank the Department of Mechanical and Industrial Engineering of the University of Brescia

\section{REFERENCES}

[1] Kim A. Advances in fire suppression systems. Construction Technology Updates. 2011;75.

[2] Jensen G. Manual fire extinguishing equipment for protection of heritage. Research report. COST Action 17 Built Heritage: Fire Loss to Historic Buildings: Riksantikvaren; Historic Scotland; 2006.

[3] Hamins AP, Bryner NP, Jones AW, Koepke GH. Research roadmap for smart fire fighting. 2015.

[4] Hamins A. Vehicle fire suppression research needs. Victoria. 2003;27.

[5] Bai A. https://www.bai.it/it/2017.

[6] Solazzi L. Applied research for weight reduction of an industrial trailer. FME Transactions. 2012;40:57-62.

[7] Union E. Directive 2009/28/EC of the European Parliament and of the Council of 23 April 2009 on the promotion of the use of energy from renewable sources and amending and subsequently repealing Directives 2001/77/EC and 2003/30/EC. Official Journal of the European Union. 2009;5:2009.

[8] Donzella G, Matteazzi S, Solazzi L. Experimental and numerical analysis of the body of a refuse collecting vehicle. International Journal of Computer Applications in Technology. 2005;24:89-97.

[9] Jamil WNM, Aripin MA, Sajuri Z, Abdullah S, Omar MZ, Abdullah MF, et al. Mechanical properties and microstructures of steel panels for laminated composites in armoured vehicles. International Journal of Automotive and Mechanical Engineering. 2016;13:3742-53.

[10] Quintiere JG. Principles of fire behavior: CRC Press; 2016.

[11] Solazzi L. Design of aluminium boom and arm for an excavator. Journal of Terramechanics. 2010;47:201-7.

[12] Solazzi L, Scalmana R. New design concept for a lifting platform made of composite material. Applied Composite Materials. 2013;20:615-26.

[13] Blanchi R, Leonard J, White N, Sargeant A, Bicknell A, Andersson S. Research into the performance of water tanks in bushfire. BlueScope Steel Limited and CSIRO--Sustainable Ecosystems (CSE) Urban Systems Program, St Lucia, Queensland, Australia 146pp. 2007.

[14] V. Krishnareddy, Modeling and Analysis of Water Tank Stand.5762:63-7.

[15] Zakaria KA, Jimit RH, Ramli SNR, Aziz AA, Bapokutty O, Ali MB. Study on fatigue life and fracture behaviour of fibreglass reinforced composites. Journal of Mechanical Engineering and Sciences. 2016;10:2300-10. 
[16] Yu D, Li X, Liu H, Dong J. Research on liquid sloshing model of partially-filled tank by nonlinear external excitation. Journal of Vibroengineering. 2015;17:322436.

[17] Jazar RN. Vehicle dynamics: theory and application: Springer; 2017.

[18] Popp K, Schiehlen W. Ground vehicle dynamics: Springer Science \& Business Media; 2010.

[19] Navarrete JAR, Otremba F. Experimental and Theoretical Modeling of Cargo Sloshing During Braking. ASME 2016 International Mechanical Engineering Congress and Exposition: American Society of Mechanical Engineers; 2016. p. V04BT5A002-V04BT05A.

[20] Kang X, Rakheja S, Stiharu I. Cargo load shift and its influence on tank vehicle dynamics under braking and turning. International Journal of Heavy Vehicle Systems. 2002;9:173-203.

[21] Azadi S, Jafari A, Samadian M. Effect of tank shape on roll dynamic response of an articulated vehicle carrying liquids. International Journal of Heavy Vehicle Systems. 2014;21:221-40.

[22] Yan G, Rakheja S, Siddiqui K. Experimental study of liquid slosh dynamics in a partially-filled tank. Journal of Fluids Engineering. 2009;131:71303-14.

[23] Noui O, Bouazara M, Richard M. Study of Liquid Motion and Pressure Forces Applied on the Walls of Partially Filled Moving Tank. ASME 2016 International Mechanical Engineering Congress and Exposition: American Society of Mechanical Engineers; 2016. p. V04AT5A034-V04AT05A.

[24] Modaressi-Tehrani K, Rakheja S, Sedaghati R. Analysis of the overturning moment caused by transient liquid slosh inside a partly filled moving tank. Proceedings of the Institution of Mechanical Engineers, Part D: Journal of Automobile Engineering. 2006;220:289-301.

[25] Koulocheris D, Dertimanis V, Spentzas K. Analysis and optimization of a fixedtank vehicle. Forschung im Ingenieurwesen. 2006;70:171-8.

[26] Patel CB, Gohil PP, Borhade B. Modeling and vibration analysis of road profile measuring system. International Journal of Automotive and Mechanical Engineering. 2010;1:13-28.

[27] Solazzi L, Scalmana R, Gelfi M, La Vecchia G. Effect of different corrosion levels on the mechanical behavior and failure of threaded elements. Journal of failure analysis and prevention. 2012;12:541-9.

[28] Eswaran UK, Saha D. M. Maity, Effect of baffles on a partially filled cubic tank: Numerical simulation and experimental validation, Comput. Struct. . 2008;87:198-205.

[29] Shao S, Li Z, Li M, Liu A. J. comparative study of different baffles on mitigating liquid sloshing in a rectangular tank due to a horizontal excitation, Eng. Comput. . doi:10.1108/EC-12--0251. 2014;32:1172-90.

[30] Yan S, Part DJ. G. Rakheja, Straight-line braking dynamic analysis of a partly filled baffled and unbaffled tank truck, Proc. Inst. Mech. Eng. Automob. Eng. . doi:10.1243/09544070JAUTO973.223:11-26.

[31] Hasheminejad MM. S.M. Mohammadi, Effect of anti-slosh baffles on free liquid oscillations in partially filled horizontal circular tanks, Ocean Eng. doihttpsdoiorg101016joceaneng09010. 2010;38:49-62.

[32] McCrum CP, Buckley CB, Oxford E. N.G. Bucknall, Principles of Polymer Publications. 1997.

[33] Gay D. Composite materials: design and applications: CRC press; 2014. 
[34] Biron M. Thermoplastics and thermoplastic composites: William Andrew; 2012.

[35] Garmstedt LA, Woodhead C. E.K. Berglund, Fatigue in Thermoplastic Ltd2003.

[36] Ashby MF. La scelta dei materiali nella progettazione industriale: Casa editrice Ambrosiana; 2007.

[37] Maria VD, Malucelli G, Mensitieri G, Ormellese M, Mariapia P, Andea S, et al. Scienza e Ingegneria dei Materiali. 2012.

[38] Kutz M. Applied plastics engineering handbook: processing and materials: William Andrew; 2011.

[39] Saechtling H. Manuale delle materie plastiche: Tecniche nuove; 2006.

[40] Solazzi L. Wheel rims for industrial vehicles: comparative experimental analyses. International Journal of Heavy Vehicle Systems. 2011;18:214-25.

[41] Timoshenko SP, Woinowsky-Krieger S. Theory of plates and shells: McGrawhill; 1959.

[42] Bajer K, Moffatt HK. Tubes, Sheets and Singularities in Fluid Dynamics: Proceedings of the NATO ARW held in Zakopane, Poland, 2-7 September 2001, Sponsored as an IUTAM Symposium by the International Union of Theoretical and Applied Mechanics: Springer Science \& Business Media; 2003.

[43] Ali NBH, Smith I. Dynamic behavior and vibration control of a tensegrity structure. International Journal of Solids and Structures. 2010;47:1285-96.

[44] Blekhman I, Kremer E. The dynamics of a complex machine assembly: Vibrationinduced drag on the rotation. Journal of Machinery Manufacture and Reliability. 2017;46:330-5.

[45] Cheli F, Diana G. Advanced Dynamics of Mechanical Systems: Allyn and Bacon Boston; 2015. 